\title{
A VARIABLE SEPARATION METHOD FOR THE CALCULATION OF THE RELIABILITY OF CONSTRUCTION
}

\author{
NGUYen VAN Pho \\ University of Civil Engineering
}

\begin{abstract}
In this paper, a variable separation method for determining the reliability of construction is proposed. Therefore, the reliability is a multiflication of two probabilities: The probability of the occurrance of load and the probability of construction in the condition the load has a determined value.
\end{abstract}

\section{Introduction}

Linearization method and iterative method have been used in the reliability theory for determining the safety probability $P_{s}$ or the reliability index $\beta$.

But it is not applicable; in many important problems, because of the great value of standard deviations or deficiency of characteristic probabilities of some random variables.

Some simple cases of variable separation method were considered in [1, 2].

In this paper, a variable separation method for determining the safety probability $P_{s}$ in construction is proposed.

For illustration, a simple axample is considered.

2. Some existing methods for determining the safety probability

\subsection{Linearization method [3]}

Let the safety margin $M$ be non-linear and given by

$$
M=f(\mathbf{x})=f\left(x_{1}, x_{2}, \ldots, x_{n}\right),
$$

where $x_{i}$ are basic variables.

Then by expanding $M$ in a series about the linearization point

$$
\mathbf{x}^{0}=\left[x_{1}^{0}, x_{2}^{0}, \ldots, x_{n}^{0}\right]^{T}
$$

( $\mathbf{x}^{0}$ is usually chosen as the expectation point) and retaining only the linear terms one gets.

$$
M=f(\mathbf{x}) \approx f\left(\mathbf{x}^{0}\right)+\sum_{j=1}^{n} \frac{\partial f}{\partial x_{j}}\left(x_{j}-x_{j}^{0}\right)
$$


where the derivatives $\frac{\partial f}{\partial x_{j}} j=1,2, \ldots, n$, are evaluated at the linearization point $\mathbf{x}_{0}^{0}$. Approximate values for the mean value $\mu_{M}$ and the standard deviation $\sigma_{M}$ can be calculated from (2.2).

$$
\begin{aligned}
\mu_{M} & =f\left(\mathbf{x}^{0}\right)+\sum_{j=1}^{n} \frac{\partial f}{\partial x_{j}}\left(\mu_{x_{j}}-x_{j}^{0}\right) \\
\sigma_{M}^{2} & =\sum_{i=1}^{n} \sum_{j=1}^{n} \frac{\partial f}{\partial x_{i}} \frac{\partial f}{\partial x_{j}} \operatorname{cov}\left[X_{i}, X_{j}\right] .
\end{aligned}
$$

Finally, the reliability index $\beta$ is defined from (2.3) and (2.4) by

$$
\beta=\frac{\mu_{M}}{\sigma_{M}}
$$

The one - one relation between the probability of failare $P_{f}$ and reliability index $\beta$ is

$$
P_{f}=\phi(-\beta) \Leftrightarrow \beta=-\phi^{-1}\left(P_{f}\right)
$$

Remark. The approximate expression (2.2) is exact in the case $\mathbf{x}$ belong to neighbourhood of $\mathbf{x}^{0}$ only.

So that, the forces caused by the wind and the earthquake can not be used.

\subsection{Iterative method [3]}

Calculation of the reliability index $\beta$ or the probability of failure $P_{f}$ must in the general case with a non-linear failure surface be done by an iterative method.

In the general $n$-dimensional case $\alpha=\left(\alpha_{1}, \ldots, \alpha_{n}\right)^{T}$ and the distance $\beta$ can be deternined by solving the $n+1$ equations

$$
\begin{aligned}
& f\left(\beta \alpha_{1}, \beta \alpha_{2}, \ldots, \beta \alpha_{n}\right)=0 \\
& \alpha_{i}=-\frac{1}{k} \frac{\partial f}{\partial Z_{j}}(\beta \alpha) \quad i=1,2, \ldots, n,
\end{aligned}
$$

where the failure surface is given by

$$
\begin{aligned}
& f\left(Z_{1}, Z_{2}, \ldots, Z_{n}\right)=0 \\
& Z_{j}=\frac{X_{j}-\mu_{x_{j}}}{\sigma_{x_{j}}} \quad j=1,2, \ldots, n
\end{aligned}
$$

and $k$ by

$$
k=\left[\sum_{j=1}^{n}\left(\frac{\partial f}{\partial Z_{j}}(\beta \alpha)\right)^{2}\right]^{1 / 2}
$$


Remark. In the practice, there are cases without enough known values $\mu_{x_{j}}$ and $\sigma_{x_{j}}$ of basic variables. We know only their frequency of the occurrence.

\section{Variable separation method}

\subsection{Conditional probability [4]}

When analyzing some phenomenon, the obsever is often concerned with that, how the occurrance of an event $A$ is influenced by that of another event $B$.

In the theory of probability, this intercorrelation is characterized by the conditionl probability $P(A / B)$ of event $A$, it is being known that $B$ actually took place

$$
P(A B)=P(A / B) \cdot P(B) .
$$

Formula (3.1) is readily extended by induction to $n$ events $A_{1}, A_{2}, \ldots, A_{n}$

$$
\begin{aligned}
P\left(A_{1}, A_{2}, \ldots, A_{n}\right)= & P\left(A_{1} / A_{2}, A_{3}, \ldots, A_{n}\right) \cdot P\left(A_{2} / A_{3}, A_{4}, \ldots, A_{n}\right) \ldots \\
& \cdot P\left(A_{1}, A_{2}, \ldots, A_{n-1} / A_{n}\right) \cdot P\left(A_{n}\right) .
\end{aligned}
$$

\subsection{Variable separtion method}

Without the loss of generality, in the reliability theory of construction, we consider the case of two groups of events. Each group corresponds to a set of random variables.

$A$ - Events of material and geometry

$B$ - Events of loads,

where event $A$ is characterized by random variables of material and geometry of construction. Event $B$ is an event of load, which has occurred and has a determined value. For example: Strong degree of typhoon (Beaufort's scalar), intensity of earthquake (MSK scalar).

So that, $P(B)$ is the multiplication of the frequency of the occurrence of event $B$ and lifetime of construction; $P(A / B)$ is probability of $A$ in the condition $B$ has a determined value.

Finally, we see that the determination of $P(A B)$ includes two steps:

Step 1 - determine $P(B)$,

Step 2 - determine $P(A / B)$.

From that, we can it as the seperation of variables method, for which (3.1) is the basic formula.

\section{Example}

A simply supported wooden beam of length $l$, rectangular cross section $b \times h$, is subjected to uniformly distributed force of its own weight intensity $q$. A concentrated force $Q$ is applied at the middle of the beam. Determine the reliability of beam. 
The maximum value of bending moment is

$$
M_{\max }=\frac{Q l}{4}+\frac{q l^{2}}{8}
$$

where $q=\gamma b h$.

We have

$$
\begin{aligned}
\sigma_{\max } & =\frac{M_{\max }}{W_{x}}=\frac{3}{4}\left[\frac{2 Q l}{b h^{2}}+\frac{\gamma l^{2}}{h}\right], \\
\sigma_{\max } & =F(Q, l, h, b, \gamma),
\end{aligned}
$$

where $Q, h, b, l, \gamma$ are normally distributed unconrelated basic variables. The safety condition is chosen

$$
\sigma_{\max } \leq \sigma_{0}
$$

where $\sigma_{0}$ is limit stress of meterial

Now we find probability $P\left(\sigma_{\max } \leq \sigma_{0}\right)$

a) Detemine $\beta$ by linearization method.

We choose the expectation point such as a linearization point.

$$
\begin{aligned}
& \mu_{Q}=10.000 \mathrm{~N}, \mu_{b}=15 \mathrm{~cm}, \mu_{h}=20 \mathrm{~cm} \\
& \mu_{1}=400 \mathrm{~cm}, \mu_{\gamma}=6 \cdot 19^{-3} \mathrm{~N} / \mathrm{cm}^{2}, \mu_{\sigma_{0}}=1.300 \mathrm{~N} / \mathrm{cm}^{2} .
\end{aligned}
$$

From that,

$$
\mu_{\sigma_{\max }}=1036 \mathrm{~N} / \mathrm{cm}^{2}, \quad \mu_{\sigma_{0}}=1.300 \mathrm{~N} / \mathrm{cm}^{2}
$$

The safety margin $M$ :

$$
\begin{aligned}
M & =\sigma_{0}-\sigma_{\max } \Rightarrow \mu_{M}=1.300-1.036=264 N / \mathrm{cm}^{2} \\
\sigma_{M} & =\sqrt{\left(\frac{\partial M}{\partial Q} \sigma_{0}\right)^{2}+\left(\frac{\partial M}{\partial h} \sigma_{h}\right)^{2}+\left(\frac{\partial M}{\partial l} \sigma_{l}\right)^{2}+\left(\frac{\partial M}{\partial b} \sigma_{b}\right)^{2}+\left(\frac{\partial M}{\partial \gamma} \sigma_{\gamma}\right)^{2}+\left(\frac{\partial M}{\partial \sigma_{0}} \sigma_{\sigma_{0}}\right)^{2}}
\end{aligned}
$$

Give: $\sigma_{Q}=2.000 \mathrm{~N}, \sigma_{l}=3 \mathrm{~cm}, \sigma_{h}=1.0 \mathrm{~cm}, \sigma_{b}=0.5 \mathrm{~cm}, \sigma_{\gamma}=50 \cdot 10^{-6} \mathrm{~N} / \mathrm{cm}^{3}$, $\sigma_{\sigma_{0}}=10 \mathrm{~N} / \mathrm{cm}^{2}$.

We have

$$
\begin{aligned}
& \left|\frac{\partial M}{\partial Q} \sigma_{0}\right|=200 \mathrm{~N} / \mathrm{cm}^{2}, \\
& \left|\frac{\partial M}{\partial l} \sigma_{l}\right|=7.5 \mathrm{~N} / \mathrm{cm}^{2}, \\
& \left|\frac{\partial M}{\partial h} \sigma_{h}\right|=105 \mathrm{~N} / \mathrm{cm}^{2} \\
& \left|\frac{\partial M}{\partial b} \sigma_{b}\right|=33.3 \mathrm{~N} / \mathrm{cm}^{2},
\end{aligned}
$$




$$
\begin{aligned}
\left|\frac{\partial M}{\partial \gamma} \sigma_{\gamma}\right| & =3 \mathrm{~N} / \mathrm{cm}^{2}, \\
\left|\frac{\partial M}{\partial \sigma_{0}} \sigma_{\sigma_{0}}\right| & =10 \mathrm{~N} / \mathrm{cm}^{2} \\
\Rightarrow \sigma_{M} & \approx 226 \mathrm{~N} / \mathrm{cm}^{2} .
\end{aligned}
$$

From this, we find the reliability index $\beta$ as follows

$$
\beta=\frac{\mu_{M}}{\sigma_{M}} \approx \frac{264}{226}=1.4 \Rightarrow P_{s}=0.91924
$$

Remark. The most important composition of $\sigma_{M}$ is $\left|\frac{\partial M}{\partial Q} \sigma_{0}\right|$, but other one are secondary comprosition.

b) Determine $\beta$ by separation of variables method.

From (3.1) we have

$$
P\left(Q, b, h, l, \gamma, \sigma_{0}\right)=P\left(b, h, l, \gamma, \sigma_{0} / Q\right) \cdot P(Q) .
$$

According to TCVN 2737-1995 (Vietnam standard - Load and Action), the value of $Q$ is chosen by maximum value of $Q$ in a determined period, Namely, 50 years, 100 years.

So that, if the lifetime of the construction is 50 years, we have

$$
P(B) \approx \frac{1}{50} \times 50=1
$$

or 100 years

$$
P(B) \approx \frac{1}{100} \times 50=\frac{1}{2}
$$

Because

$$
\begin{aligned}
& P_{s}\left(b, h, l, \gamma, \sigma_{0} / Q\right)=1-P_{f}\left(b, h, l, \gamma, \sigma_{0} / Q\right), \\
& P_{s}\left(b, h, l, \gamma, \sigma_{0} / Q\right) \Leftrightarrow \beta=\frac{226}{106.5} \approx 2.1
\end{aligned}
$$

we have

$$
P_{f}=0.01786 \text { and } P_{s}=0.98214
$$

Finally,

$$
P_{s}\left(Q, b, h, l, \gamma, \sigma_{0}\right)=0.98214 \times 1=0.98214
$$


or

$$
P_{s}=0.98214 \times 0.5=0.491070 \text {. }
$$

\section{Conclusions}

The proposed variable separation method not only is exacter than the linearization method but also suitable for determining of the reliability of construction as well.

The obtained results in this paper can apply to the other field of the reliability theory.

This research has been supported by a grant of the Fundamental Research Program in Natural sciences.

\section{REFERENCES}

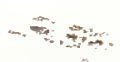

1. Nguyen Van Pho, Nguyen Le Ninh, Le Van Thanh. Reliability of structures in seismic regions. Froceedings of the sixth National Conference on Solid Mechanics, Hanoi, 26-27 November, 1999 (in Vietnamese).

2. Le Ngoc Hong, Nghiem Quang Ha. The sensitivity of paramester in strength and stability problems. Proceedings of the Conferenee on structural engineering and construction technology - 2000 (in Vietnamese). Hanoi 12/2000.

3. Palle Thoft - Christensen, Yoshisada Murotsu. Application of structural systems Reliability Theory. Springer - Verlag Berlin Heidelberg New York Tokyo 1986.

4. Nathabandu T. Kottegoda, Renzo Rosso. Statistics, Probability and Reliability for Civil and Environmental Engineers. The McGraw - Hill Companies, Inc. 1997.

Received August 2, 2001

\section{PHƯƠNG PHÁP TÁCH BIẾN TRONG TÍNH TOÁN ĐỘ TIN CẬY CƯA CÔNG TRÌNH}

Trong bài này, tác giả đề nghị phương pháp tách biến để tính độ tin cậy của công trình. Việc tách biến như vậy sẽ thuân lợi hơn, vì có thể dùng dược phương pháp tuyến tính hóa cho nhóm biến số có độ lệch chuẩn béé, đồng thời cho phép tính dễ dàng với nhóm các biến số thiếu các đặc trưng xác suất như tải trọng gió hoặc dộng dất v.v...

Để minh họa cho phương pháp, một thí dụ đơn giản đã được xét tŷ̀ mí. 